\title{
Benign paroxysmal tonic upgaze of childhood with ataxia
}

INSERM

\section{Source}

INSERM. (1999). Orphanet: an online rare disease and orphan drug data base. Benign paroxysmal tonic upgaze of childhood with ataxia. ORPHA:1179

Benign paroxysmal tonic upgaze of childhood with ataxia is a rare paroxysmal movement disorder characterized by episodes of sustained, conjugate, upward deviation of the eyes and down beating saccades in attempted downgaze (with preserved horizontal eye movements) which is accompanied by ataxic symptomatology (unsteady gait, lack of balance and movement coordination disturbances) in an otherwise healthy individual. Bilateral vertical nystagmus is associated. Symptoms generally disappear spontaneously within 1-2 years after onset. 